\title{
Performance Analysis Of A Grid-Connected Solar Photovoltaic Wind Hybrid Energy System
}

\author{
Shabbier Ahmed Sydu ${ }^{\text {a }}$, Dr. A A Ansari ${ }^{b}$ \\ a Research Scholar, Dept. of Electrical \& Electronics Engineering, \\ Sri Satya Sai University of Technology \& Medical Sciences, Sehore, Bhopal Indore Road, Madhya Pradesh, India \\ ${ }^{\mathbf{b}}$ Research Guide, Dept. of Electrical \& Electronics Engineering, \\ Sri Satya Sai University of Technology \& Medical Sciences, Sehore, Bhopal Indore Road, Madhya Pradesh, India
}

Article History: Received: 11 January 2021; Accepted: 27 February 2021; Published online: 5 April 2021

\begin{abstract}
Electrical energy becomes necessary for human being. Generation of electrical energy mostly depends on fossils fuel, they are limited in nature and also responsible for environmental pollution. Renewable energy resources provides a better alternative for future. In comparison to conventional energy resources economical aspect is a major issue of renewable energy sources with the feasibility and efficiency. This paper investigates the performance analysis and control of Photovoltaic (PV)wind hybrid system connected to electrical grid and feeds large plant with critical variable loads. The technique of extracting maximum power point is applied for the hybrid power system to capture maximum power under varying climatic conditions. Moreover, Control strategy for power flow is proposed to supply critical load demand of plant. The Dynamic performance of the proposed hybrid system is analyzed under different environmental conditions. The simulation results have proven the effectiveness of the proposed maximum power point tracking (MPPT) strategies in response to rapid variations of weather conditions during the day.
\end{abstract}

Keywords: Photovoltaic, MPPT control, Hybrid energy, wind turbine.

\section{Introduction}

One of the most promising applications of renewable energy technology is the installation of hybrid energy systems in remote areas, where the grid extension is costly and the cost of fuel increases drastically with the remoteness of the location. Recent research and development in Renewable energy sources have shown excellent potential, as a form of supplementary contribution to conventional power generation systems. In order to meet sustained load demands during varying natural conditions, different energy sources and converters need to be integrated with each other for extended usage of alternative energy. Renewable energy sources, such as photovoltaic, wind energy, or small scale hydro, provide a realistic alternative to engine-driven generators for electricity generation in remote areas. It has been demonstrated that hybrid energy systems can significantly reduce the total lifecycle cost of standalone power supplies in many situations, while at the same time providing a more reliable supply of electricity through the combination of energy sources. The widely used term hybrid energy system (HES) describes a stand-alone energy system, which combines renewable and conventional energy sources with lead-acid batteries for chemical storage, power conditioning equipment and a controller. The controller and power conditioning units are used to maintain the grid quality power. Alternatively, such systems are also known as integrated renewable energy systems (IRES).

\section{Block Diagram for PV and wind hybrid system}

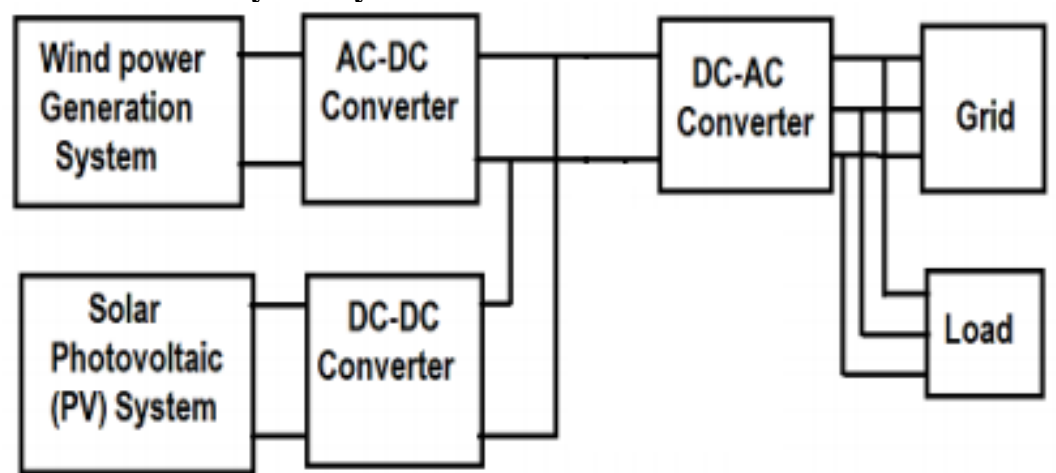

Solar Panel

Figure 1. Simple block diagram for Solar PV and Wind hybrid Energy system.

Solar power is the cleanest, most reliable from of energy available, and it can be used in several forms to help power your home or industries. Solar powered photovoltaic (PV) panels convert the sun rays into electrical energy by exciting electrons in silicon cells using the photons of light from the sun. Most of the solar panels placed on the root to get sun rays on panel. The solar panels also known as modules contain photovoltaic cells 
made from silicon that transform incoming sunlight into electricity than heat. The energy of solar depends on the installation panel on home and industries.

\section{Windmill}

Wind power converts the kinetic Energy in wind to generated electricity or mechanical power. There are currently two different kinds of wind turbines horizontal axis wind turbines (HAWT) and vertical axis wind turbines (VAWT). Converting wind to mechanical energy wind is converted by the blades of wind turbines. The HAWT are the most common displaying the propeller or 'fan-style' blades and VAWT are usually in an 'eggbeater' style blades.

\section{Charging Controller}

A charge controller, charge regulator or battery regulator limits the rate at which electric current is added to or drawn from electric batteries. It prevents over charging and may protect against over voltage which can reduce battery performance or lifespan. And safety risk. It is used to maintain the proper charging voltage on the batteries.

\section{Inverter}

Inverter is an electronic device or circuitry that changes direct current (DC) to alternating current (AC). A typical power inverter device or circuit requires a relatively stable DC power source capable of supplying enough current for the intended power demand. An inverter can produce a square wave, modified sine wave, pulse width modulation.

\section{Grid}

An electrical grid is an interconnected network for delivering electricity from producers to consumers. If consists of generating stations that produce electrical power, high voltage transmission lines that carry power from distant sources to demand centers, and distribution that connect individual customers.

\section{Solar photovoltaic /wind based hybrid energy system}

An arrangement of the renewable power generation with appropriate storage and feasible amalgamation with conventional generation system is considered as hybrid energy system or some time referred as a micro grid. This system may be any probable combination of Photovoltaic, wind, micro turbines, micro hydro, conventional diesel generation, battery storage, hydrogen storage and Fuel Cell in gridconnected or off grid arrangement. An assembly of interconnected loads, conventional distributed energy resources like distributed generators (DG), renewable resources and energy storage systems in a specified boundary as a controllable single entity referred as micro grid. It may be eternally connected to grid, or isolated by grid. There are worldwide numerous remote communities those are not directly connected to grid, and fulfill electricity demand from distributed generators based on fossil fuel in isolated Microgrids. An assimilated arrangement of solar PV and wind renewable energy resources is discussed which is slightly different from the concept of microgrid.

Solar Photovoltaic /Wind based Hybrid Energy System shows its adequacy to provide the essential electrical demand for off grid utilization. The at most imperative feature of a Solar Photovoltaic (PV) and Wind based Hybrid Energy System is that it uses at least two sustainable power sources which enhances reliability, efficiency and financial restrictions emerges from single energy resources of renewable nature. Solar Photovoltaic and Wind based Hybrid Energy System is considered as amalgamation of solar PV panel, Wind mills, charge controller, storage system, power conditioning units, diesel based generator set and load. The assessment of performance of Hybrid system can be done by recreating their models at Simulink platform for the accessible insulation, speed of wind, electrical load and various components. The essential objective for evaluation of Hybrid System are building up the suitable models for various components and their simulation in a sequential manner as firstly availability of speed wind, accessibility of sunlight and the demand of load models are simulated after that model of battery storage and diesel generator can be Simulated. Last strides in the entire procedure of assessment is deciding the coveted criteria and exploring the optimum structure of system. The optimal hybrid system arrangement should satisfy and compromise the objectives of power reliability and cost of system. The load demand frequently considered as limitation of the optimization issue and ought to be totally satisfied. The solar PV/wind hybrid system is mostly reliant on execution of individual segments. To estimate the performance of solar PV/wind hybrid system, individual components are modeled initially after that entire system evaluated to meet the demand. In general key aspects to analyze a hybrid system are hybrid system configuration with respect to the available resources, the optimization of the available renewable resources exploitation and the optimization of the output power quality.

Solar energy and wind energy are analogous to each other in nature and both are well appropriate to develop a hybrid system. Availability of solar radiations are relatively greater in summer, winds are more accessible in the evening times of winters.

This hybrid renewable energy systems give a more reliable output throughout the year can be planned to fulfill craved qualities on more decreased possible cost. The constraints of Photo voltaic system, the assessed energy of wind energy system and the battery storage are the majorly considered parameters for evaluation of solar and 
wind based hybrid energy system. In addition, the precise angular attitude of Photo voltaic panels and the tower height of wind turbines are considered for achieving the minimum levelised cost of energy. Load demand play a very important role in establishment of solar PV/wind hybrid renewable energy system provides more reliable power for off-grid and standalone applications compared to individual systems. The most of the reviewed studies are about the alone Solar Photovoltaic /Wind based Hybrid Energy System and few studies are available for grid connected system. The unsatisfied load request is procured from the grid. Along this way the hybrid system became noticeably trustworthy. The stand-alone systems with storage infused surplus energy to the grid at a prime cost. Along these lines, the grid connected system becomes more financially acceptable.

\section{LITERATURE REVIEW}

R. Maouedjaet al (2020): This paper presents experimental results from the operation of a test bench constituted of a PV-Wind hybrid system. This device includes photovoltaic (PV) and wind subsystems, battery energy storage, load and a hybrid system, controller for battery charging and discharging condition. The system includes a $600 \mathrm{~W}$ PV array, $1 \mathrm{KW}$ wind turbine; in the day the energy produced is stored in a battery bank $24 \mathrm{~V} / 1600 \mathrm{Ah}$ and used for public lighting at night, with an average daily energy consumption of $2640 \mathrm{Wh}$. The experimental set up has been realized in the Research Unit in Renewable Energies in Saharan Medium, Adrar (South of Algeria). The photovoltaic panel group constitutes the primary energy supplier of the system; while the wind turbine is the secondary supplier since the contribution of wind turbine is small as compared to the share of the photovoltaic subsystem.

P. Nagadeviet al (2019): For fulfilling the global energy demand hybrid energy system is the better option. Hybrid energy system is the integration of wind, solar, hydro power renewable energy sources to that of existing transmission distribution system. The rapid consumption, limited resources of fossil fuel, global warming, and causes damage to the environment \& ecosystem, creates a higher demand for clean and sustainable energy sources like: wind, sea, sun, biomass etc. with high efficiency and less maintenance.The wind and solar PV system are connected to the common load through DC-DC Boost converter. In the stand-alone mode the converter needs to maintain constant voltage and frequency regardless of load unbalance or quality of the current which can be highly distorted, if the load is non-linear. In this paper a flexible simulation model for a hybrid offgrid photovoltaic or the wind using Mat lab/Simulink is presented, the model is thoroughly explained and the components are presented in great details. This paper describes the Simulation and analysis of hybrid system consisting of wind and solar PV system connected to grid. By using the simulation results we can analyze the performance of the solar PV wind hybrid energy system. The main objective of this paper is to model a grid connected hybrid power system together with combining a diesel generator. In this model, outputs of these two sources are determined. The input for these two sources are solar radiation and wind speed. The modeling of both PV system and wind is done. The analysis of the output of system is made. MATLAB/SIMULINK is used to simulate the system and to evaluate its performance of the system

\section{PROPOSED METHODOLOGY}

Hybrid system usually consists of two or more renewable energy source to provide increased efficiency of the system and also greater balance in energy supply. The proposed configuration of the PV/Wind hybrid system is depicted in Figure 4.1. It is composed of two blocks: the power block and control block. The power block consists of PV array and wind turbine as sources of energy. The PV energy conversion system is equipped with its DC-DC boost converter in order to step up array output voltage to the required voltage level (500V DC). In addition, The DC-AC inverter that converts $500 \mathrm{~V}$ DC to $260 \mathrm{~V}$ AC and keeps unity power factor. The wind energy conversion includes doubly fed induction generator (DFIG), rotor side converter and grid side converter. Transformer is used in order to raise output voltage to point of common coupling (PCC) voltage. Concerning the control block, manytechniques have been investigated in order to extract maximum power, keep unity power factor and regulate DC link voltage. 


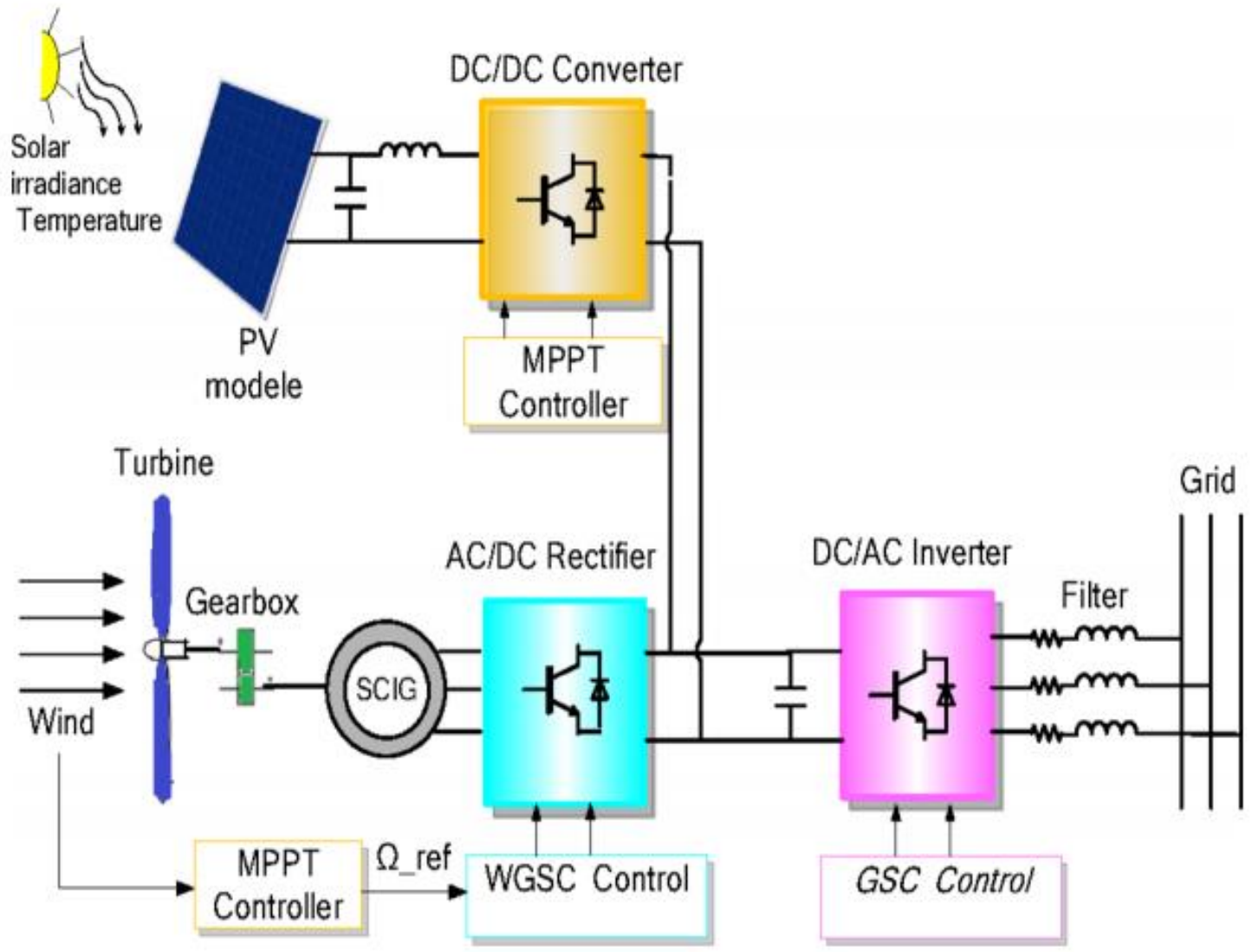

Figure 2 Proposed PV - wind Hybrid system

\section{PV generator model}

The electrical modelling of a PV module has been introduced based on the Shockley diode as shown in Figure 3

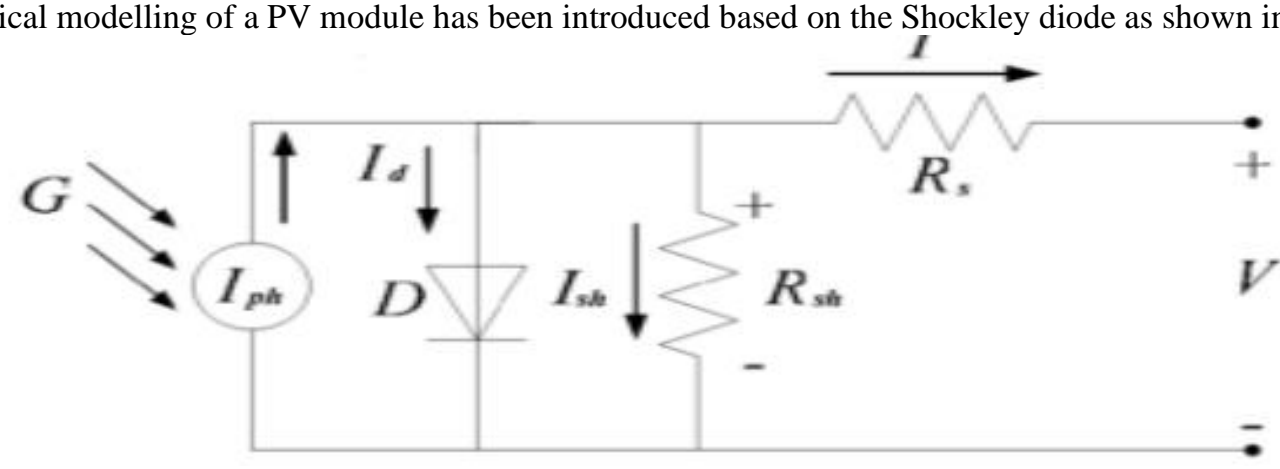

Figure 3 PV cell model

By means of the photoelectric phenomena, the solar cell can directly convert the sunlight to electric power. One diode model is used to represent the PV cell. The photovoltaic cell model consists of a current source in parallel with a diode, a shunt resistance and a series resistance.

$$
\begin{aligned}
& I_{P V}=I_{P h}-I_{s a t}\left\{\exp \left[\frac{q\left(V_{P V}+I_{P V} R_{S}\right)}{A K T}\right]-1\right\} \frac{V_{P V}+I_{P V} R_{S}}{R_{S h}} \\
& I_{P h}=\left[I_{P h, S T C}+K_{i}\left(T-T_{S T C}\right)\right]\left(\frac{G}{G_{S T C}}\right) \\
& I_{\text {sat }}=I_{\text {sat }, S T C}\left(\frac{T_{S T C}}{T}\right)^{3} \exp \left[\frac{q E_{g}}{A K}\left(\frac{1}{T_{S T C}}-\frac{1}{T}\right)\right]
\end{aligned}
$$

Figure 4 depicts the $(\mathrm{I}-\mathrm{V})$ and $(\mathrm{P}-\mathrm{V})$ characteristics of $\mathrm{PV}$ array obtained through modelling under various solar irradiation intensity conditions. 
(i)

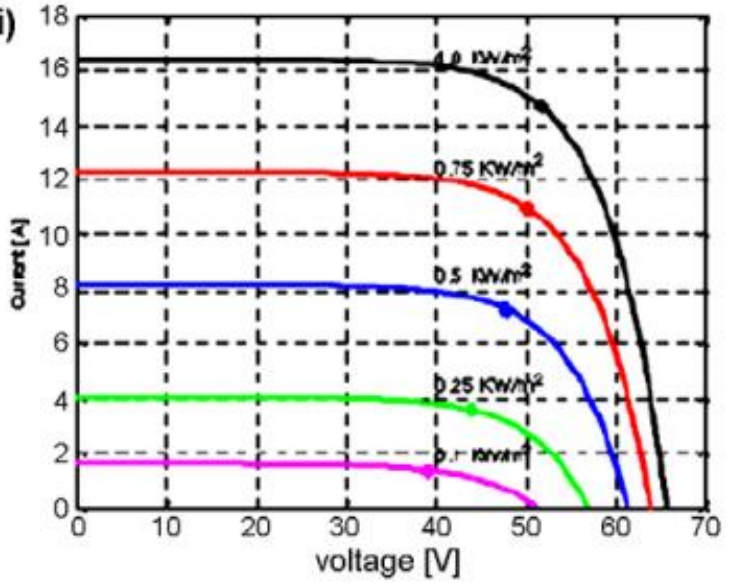

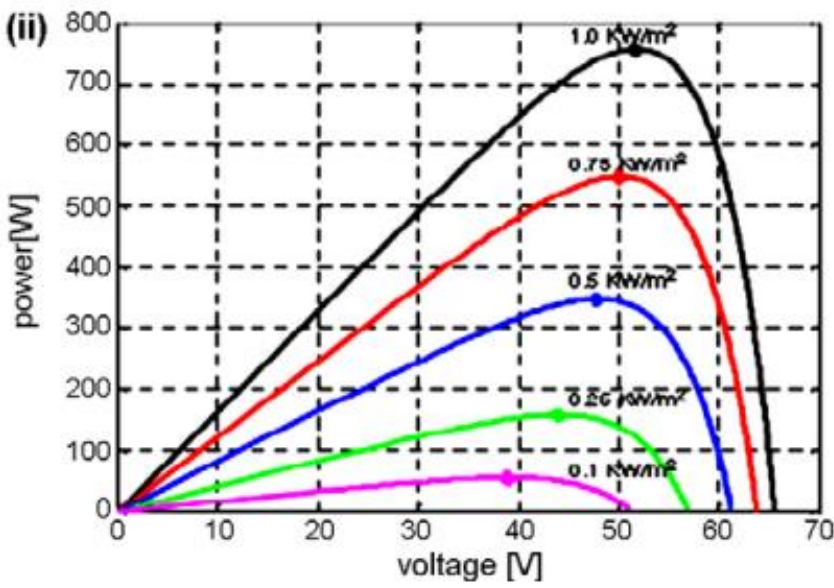

Figure 4(i) I-V characteristics of PV module and (ii) $P-V$ characteristics of $P V$ module.

\section{Wind Energy system model}

In case of wind Energy generation characteristics, site characteristics, load demand, meteorological data and economical data are utilized as contribution for the improvement of wind energy framework. It is recognized that simulation model require hour-by-hour information of wind speed, due to inaccessibility of such types of data for every location and time. Some alternative simulation programs have been created for long-term performance. The utilized input data and their statistical treatment for wind turbines, load demand, diesel generators units and energy storage and presented the developed models and applied to evaluate the energies produced by the wind turbines and diesel generators for diverse wind data. The existence of an energy reserve taken into account constituted by lead batteries for odd conditions power generation by wind turbine. It is very important to select a suitable model for power output simulations of wind generation system. A simplified simulation model of wind generation system can be developed by considering speed of wind,hub height and law component of power as constrain parameters. The varying nature of wind generated electrical power shows in behavior which leads to explore new methods like quadratic model or Weibull distribution for determining wind power output. some of recent work wind power output is given by the hour based quadratic representation using power rated, speed characteristics based on cut-in, rated and cutoff speed.

\section{Power Quality}

Intermittent energy from solar and wind has a huge impact on loads security since those loads have no connection with grid. So, any shortfall in power generation from those sources may leave the connected loads without power supply. Voltage fluctuation, frequency fluctuation and harmonics are major power quality issues. The voltage fluctuation as a result of irradiation changes could make the PV system unstable which will have an impact on the overall reliability of the hybrid stand-alone solar PV and wind system. The same thing is applicable with respects to variations in wind speed which affects the performance of the wind system and ultimately the overall hybrid system. Accurate forecasting and scheduling systems can minimize the impacts. The frequency stability of a generator should be taken into account based on load requirements and whether the generator is connected to $\mathrm{AC}$ loads with critical power frequency requirements or not. High frequency fluctuations can be suppressed by using storage devices such as electrolytic double layer capacitor. An experimental investigation was carried out to assess the wind impacts on PV module. The mean pressure magnitude on the PV module was measured for both cases; under smooth wind exposure and open terrain wind exposure where the magnitude was smaller in the latter case.

\section{RESULTS}

Wind and Solar hybrid Power system is the collective power generating system by wind mill and solar energy panel. For different wind speed and solar irradiation the output of the universal bridge inverter according to that we have to change. This system achieve by changing the gate pulses which are given to the universal bridge inverter. The output of the universal bridge inverter is directly connected to the grid and the load. 


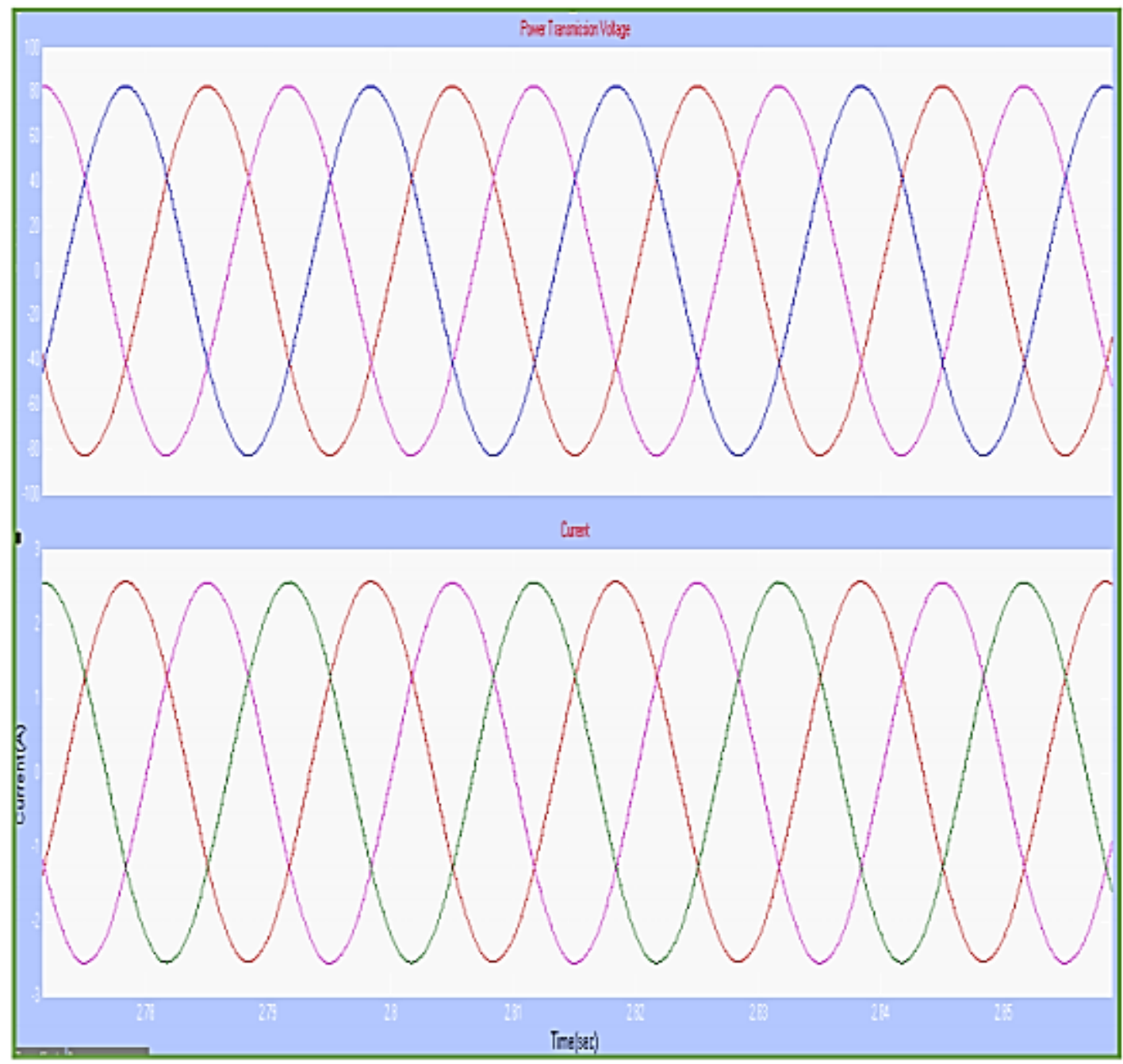

Figure 5Waveform of Output Voltage and Current at grid side

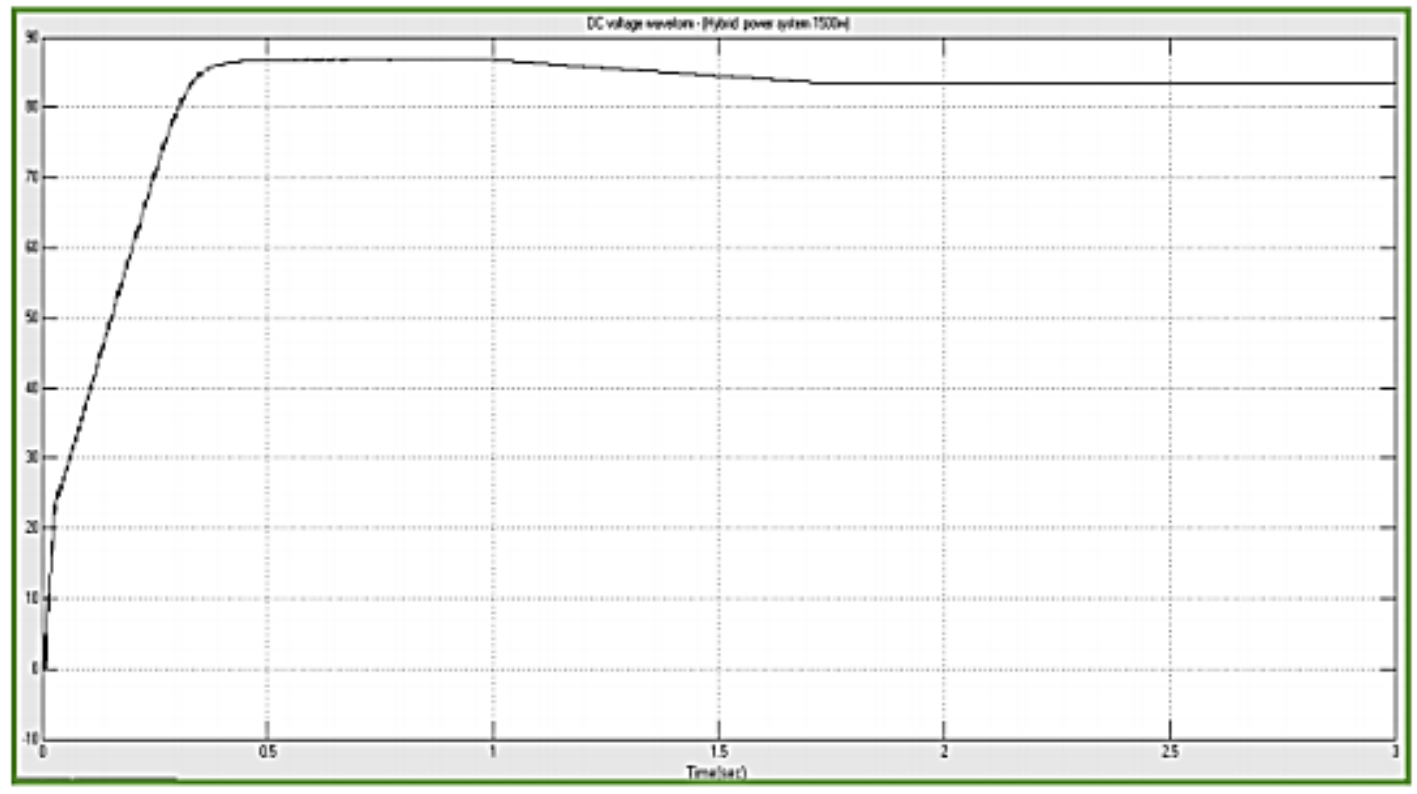

Figure 6 DC Output voltage Waveform of Hybrid System 


\section{CONCLUSION}

By integrating the two resources into an optimumcombination, the impact of the variable nature of solar and wind resources can be partially resolved and the overall system becomes more reliable and economical to run.The MPPT technique is applied to the PV system and the wind system to capture the maximum power under varying climatic conditions. The simulation results have proven the robustness of the proposed hybrid system in response to rapid changes in solar radiation and wind speed conditions. This proposed system facilitates improvement in power quality which ensures continuous and reliable supply to loads. Therefore, this system can tolerate the rapid changes in load and environmental conditions and suppress the effects of these fluctuations and provides optimum utilization of available resources.

\section{REFERENCES}

1. R. Maouedja, A. Mammeria , M.D. Draoua and B. Benyoucef, "Performance evaluation of hybrid Photovoltaic-Wind power systems". The International Conference on Technologies and Materials for Renewable Energy, Environment and Sustainability, TMREES14

2. P.NAGADEVI and Y.MAHALAKSHMI REDDY (2019), "Performance Analysis, Modeling and Simulation Of Grid Connected Solar PV - Wind Hybrid Energy System". INTERNATIONAL JOURNAL OF PROFESSIONAL ENGINEERING STUDIES. Volume VII /Issue 5 / NOV 2019.

3. S. Jahdi, L. L. Lai, and D. Nankoo, "Grid integration of wind-solar hybrid renewables using AC/DC converters as DG power sources," Proc. IEEE World Congress on Sustainable Technologies (WCST 11), IEEE Press, pp. 171- 177, November (2020)

4. Castle, John A., James M. Kallis, Sally M. Moite, and Neil A. Marshall, "Analysis of Merits of Hybrid Wind/Photovoltaic Concept for Stand-Alone Systems," in 15th IEEE Photovoltaic Specialists Conference, vol. 738-744, May 2016

5. Yang, H., Z. Wei, and L. Chengzh, "Optimal design and technoconomic analysis of a hybrid solar-wind power generation system," in Applied Energy, vol. 86, pp. 163-169, Feb. 2019.

6. Farahat S, Jahromi MAY, Barakati SM. Modeling and sizing optimization of stand-alone hybrid renewable energy systems. In: International conference on mechanical, nanotechnology and cryogenics engineering (ICMNC). Kuala Lumpur, Malaysia; 2018.

7. PragyaNema, SarojRangnekar "A current and future state of art development of hybrid energy system using wind and PV-solar" in November 2016.

8. Wei Jhou, Hoxing Yang "A Novel Optimization sizing model for hybrid solar-wind power generation system"in International Journal in, vol. 81, Number 1. 2017

9. B. Ernst, F. Reyer, and J. Vanzetta, "Wind power and photovoltaic prediction tools for balancing and grid operation," Proc. Integration of Wide-Scale Renewable Resources Into the Power Delivery System, CIGRE/IEEE PES Joint Symposium, IEEE Press, pp. 1-9.

10. E. Koutroulis, D. Kolokotsa, A. Potirakis, and K. Kalaitzakis, "Methodology for optimal sizing of standalone photovoltaic/windgenerator systems using genetic algorithms" Solar Energy, 80, 1072- 1088 (2016) DOI: 10.1016/j.solener.2005.11.002 